\title{
Uncovering the role of p53 splice variants in human malignancy: a clinical perspective
}

This article was published in the following Dove Press journal:

OncoTargets and Therapy

19 December 2013

Number of times this article has been viewed

\author{
Sylvanie Surget ${ }^{1,2}$ \\ Marie P Khoury ${ }^{1,2}$ \\ Jean-Christophe Bourdon ${ }^{1,2}$ \\ 'Dundee Cancer Centre, ${ }^{2}$ Jacqui Wood \\ Cancer Centre, Ninewells Hospital, \\ University of Dundee, Dundee, UK
}

\begin{abstract}
Thirty-five years of research on $\mathrm{p} 53$ gave rise to more than 68,000 articles and reviews, but did not allow the uncovering of all the mysteries that this major tumor suppressor holds. How p53 handles the different signals to decide the appropriate cell fate in response to a stress and its implication in tumorigenesis and cancer progression remains unclear. Nevertheless, the uncovering of $\mathrm{p} 53$ isoforms has opened new perspectives in the cancer research field. Indeed, the human TP53 gene encodes not only one but at least twelve p53 protein isoforms, which are produced in normal tissues through alternative initiation of translation, usage of alternative promoters, and alternative splicing. In recent years, it became obvious that the different p53 isoforms play an important role in regulating cell fate in response to different stresses in normal cells by differentially regulating gene expression. In cancer cells, abnormal expression of p53 isoforms contributes actively to cancer formation and progression, regardless of TP53 mutation status. They can also be associated with response to treatment, depending on the cell context. The determination of p53 isoform expression and p53 mutation status helps to define different subtypes within a particular cancer type, which would have different responses to treatment. Thus, the understanding of the regulation of p53 isoform expression and their biological activities in relation to the cellular context would constitute an important step toward the improvement of the diagnostic, prognostic, and predictive values of p53 in cancer treatment. This review aims to summarize the involvement of p53 isoforms in cancer and to highlight novel potential therapeutic targets.
\end{abstract}

Keywords: p53, isoforms, p63, p73, alternative splicing, cancer

\section{Introduction}

The tumor suppressor p53 has been dubbed the "guardian of the genome", given its crucial role in maintaining genetic stability and the prevention of cancer formation. To assume this role, once activated after cell injury, p53 induces a number of cellular responses, such as cell repair and survival or programmed cell death.

In the late nineties, two p53-related proteins, p63 and p73, which share strong structural, biochemical, and biological homologies with p53, were identified. Six and at least 14 protein isoforms are expressed from the $p 63$ and $p 73$ genes, respectively, with $\Delta \mathrm{Np} 63$ and $\Delta \mathrm{Np} 73$ being the predominant isoforms expressed in several human cancers. ${ }^{1,2}$ In vivo studies carried out with different p53, p63, and/or p73 mouse models highlight the synergistic effects of the p53 family in tumor suppression. ${ }^{3}$

Canonical p53 protein (also named p53, FLp53, p53 $\alpha$ or TAp53 $\alpha$ ) was the first p53 isoform to be identified. After being thought for 25 years to be the only isoform encoded by the human TP53 gene, we and others have described that at least twelve p53
Correspondence: Jean-Christophe Bourdon

Dundee Cancer Centre, Division of Cancer Research, University of Dundee, James Arrott Drive, Dundee DDI 9SY, UK

Tel +44 I382383285

Fax +44I382740 359

Email j.bourdon@dundee.ac.uk 
protein isoforms are encoded by the TP53 gene (p53, p53 $\beta$, $\mathrm{p} 53 \gamma, \Delta 40 \mathrm{p} 53 \alpha, \Delta 40 \mathrm{p} 53 \beta, \Delta 40 \mathrm{p} 53 \gamma, \Delta 133 \mathrm{p} 53 \alpha, \Delta 133 \mathrm{p} 53 \beta$, $\Delta 133 \mathrm{p} 53 \gamma, \Delta 160 \mathrm{p} 53 \alpha, \Delta 160 \mathrm{p} 53 \beta$, and $\Delta 160 \mathrm{p} 53 \gamma) . \mathrm{p} 53$ isoforms are obtained through alternative initiation of translation, usage of alternative promoters, and alternative splicing. p53 protein isoforms all share a common part of the deoxyribonucleic acid (DNA)-binding domain (of canonical p53 protein), and contain distinct transactivation and C-terminal regulatory domains, enabling them differentially to regulate gene expression. ${ }^{4}$

p53 isoforms are differentially expressed in several human cancer types and were shown to exhibit several biological functions, modulating p53 transcriptional activity and tumor-suppressor functions. The biological activities of p53 isoforms, as well as their clinical implication in cancer, will be the subject of this review.

\section{Physiological roles of $\mathrm{p} 53$ p53 family members: $p 63$ and p73}

The p53-related proteins p63 and p73 share significant structural and functional homologies with p53, particularly in the DNA-binding domain, including conservation of all essential DNA contact residues. ${ }^{5-7}$ p63 and p73 contain the three typical domains of a transcription factor: the aminoterminal transactivation domain (TAD), the DNA-binding domain (DBD) and the carboxyl-terminal oligomerization domain (OD). These two p53 homologues are involved in cellular responses to stress and development. ${ }^{8}$ They possess several functional properties and work together with p53 to regulate tumorigenesis. In response to stress signals, they can bind p53-target genes and induce their transcription. In the absence of cellular stress, p63 and p73 have important roles in the regulation of cellular differentiation and development. While p63 is important in the development of squamous epithelia, p73 has been shown to be involved in neuronal differentiation as well as nervous and olfactory system development. p53 family members are important in the development of congenital abnormalities in humans. ${ }^{9}$ Importantly, not only the individual roles of each p53 family member but also their interaction with one another are important for tumor suppression. ${ }^{3}$

\section{p53, a tightly regulated major tumor suppressor}

$\mathrm{p} 53$ is a $53 \mathrm{kD}$ protein that is activated in response to alteration of normal cell homeostasis, including DNA damage, nutrient starvation, heat shock, virus infection, $\mathrm{pH}$ change, hypoxia, and oncogene activation. ${ }^{10}$ p53 maintains genetic stability by regulating different processes, such as cell-cycle arrest, DNA synthesis and repair, programmed cell death, and energy metabolism. In the absence of stress signals, p53 protein is present at low levels, due to a dynamic and finely tuned balance between its transcription and its degradation. This balance is of great importance, as too much p53 can be lethal to cells, whereas too little can allow cancers to develop. p53 protein is tightly regulated in response to various cellular stresses at the transcriptional and translational level and by different posttranslational modifications, such as phosphorylation, acetylation, ubiquitination, neddylation, sumoylation, and methylation. ${ }^{11}$ In particular, p53 protein level is regulated by ubiquitin ligases, such as HDM2 (also known as MDM2, for mouse double minute 2) and Pirh2. ${ }^{12,13}$

All those modifications control the activation of p53 protein, as well as its subcellular localization, degradation, the choice of its protein partners, and therefore the outcome of the cellular response after stress: life or death. Indeed, after stress, p53 is activated by numerous mediators upstream in the pathway (ATM, CHK, ARF, among others), inducing an accumulation of $\mathrm{p} 53$ protein as a result of the inhibition of its repressors, such as MDM2 (Figure 1).

p53 is a transcription factor that binds directly and specifically as a tetramer to p53-responsive elements on DNA to induce or repress gene expression. ${ }^{14,15}$ It is estimated that more than 3,600 target genes are directly regulated by $\mathrm{p} 53 .{ }^{16}$ Physiologically, p53 prevents damaged cells from proliferating. This function is of great benefit, as damaged cells are more likely to contain mutations and therefore exhibit abnormal cell growth, which can lead to the development of cancer. ${ }^{17,18}$

Depending on the type of stress, activated p53 triggers either cell-cycle arrest and DNA repair or cell death, but the mechanism determining the choice between these fates has not yet been elucidated.

\section{p53 biological activities as the "guardian of the genome"}

Once activated, p53 can induce cell-cycle arrest in either the $G_{1}$ or $G_{2}$ phase of the cell cycle. Indeed, following DNA damage, p53 induces $p 21$, a cyclin-dependent kinase inhibitor that mediates cell-cycle arrest at the $G_{1}$ and $S$ phases of the cell cycle, allowing DNA repair. On the other hand, p53 can activate GADD45 (growth arrest and DNA damage), which regulates cell-cycle arrest in the $\mathrm{G}_{2} / \mathrm{M}$ phases. ${ }^{19}$ Other p53-target genes also involved in cell-cycle control include miR-34a and the 14-3-3 proteins. Altogether, the presence of a functional p53 is important for the different checkpoints of the cell cycle, thereby giving cells time to repair DNA damage. ${ }^{20}$ 


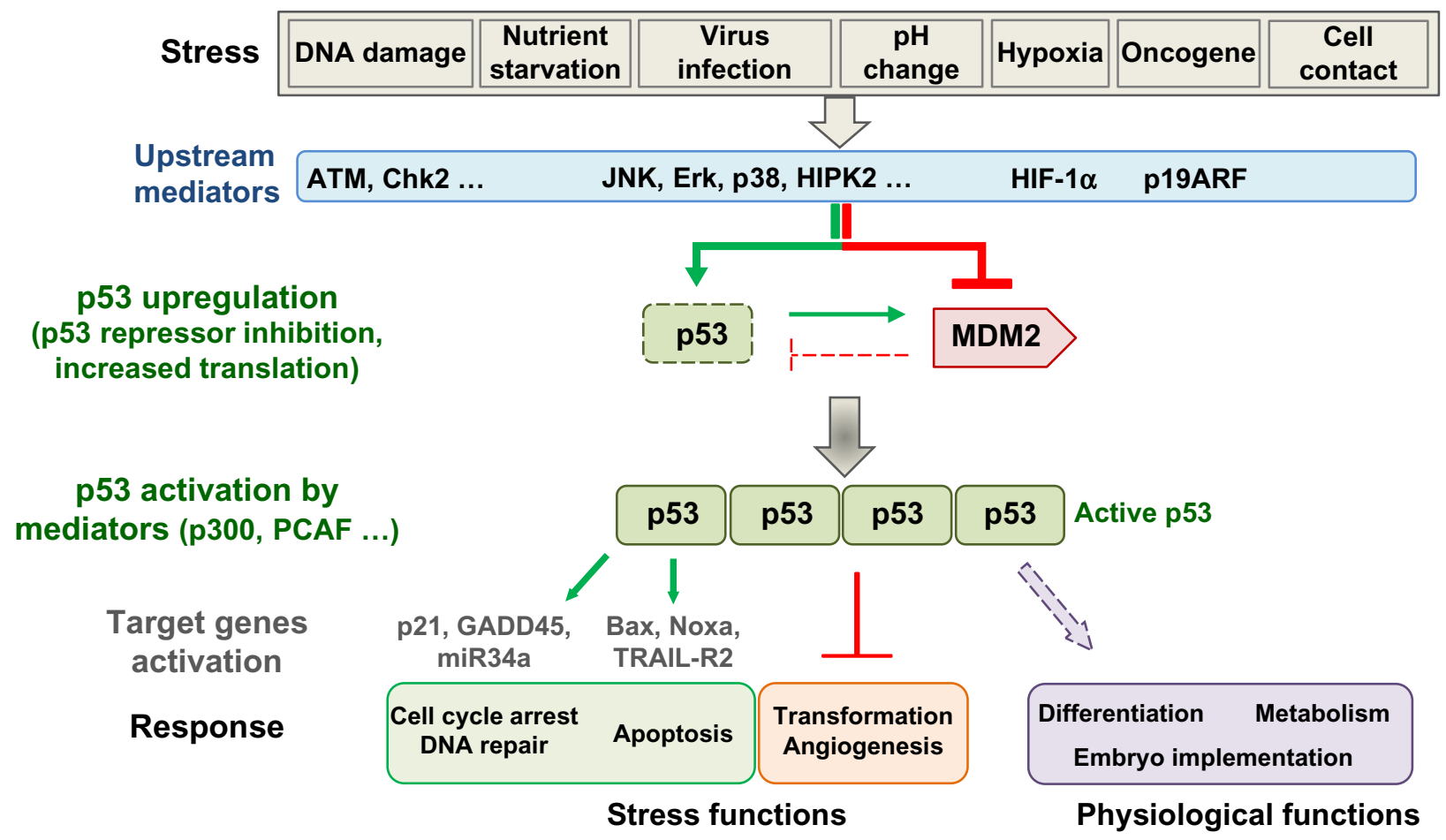

Figure I The p53 pathway. Different cellular stresses induce the activation of the upstream mediators (eg, ATM, Chk2, pl9ARF), which upregulate p53 by inhibiting p53 interaction with MDM2, its main ubiquitin ligase. Then, p53 activated by mediators activates or represses its target genes according to the final outcome expected. In the absence of stress, $\mathrm{p} 53$ regulates many other physiological functions.

Abbreviations: DNA, deoxyribonucleic acid; ATM, ataxia telangiectasia mutated; JNK, c-Jun N-terminal kinase; HIPK2, homeodomaininteracting protein kinase 2; HIFla, hypoxia-inducible factor-la; MDM2, mouse double minute 2; PCAF, p300/CBP-associated factor; GADD45, growth arrest and DNA damage; TRAIL-R2, TNF-related apoptosis-inducing ligand-receptor2.

When damage is beyond repair, $\mathrm{p} 53$ triggers programmed cell death, and it is thought that p53-mediated apoptosis is the primary cause of tumor suppression. Many genes involved in apoptosis are p53-target genes, especially in the intrinsic pathway of apoptosis. Indeed, some of the proapoptotic members of the Bcl-2 family (Bax, Bid, Noxa, and Puma), as well as the mitochondrial proteins apoptotic protease activating factor 1 and second mitochondria-derived activator of caspases/DIABLO can be upregulated by $\mathrm{p} 53 .{ }^{21}$ Conversely, the expression of antiapoptotic proteins, such as Bcl-2, Bcl-xL, or survivin can be repressed by $\mathrm{p} 53$. Regarding the extrinsic pathway of apoptosis, it has been shown that expression of the death receptors tumor necrosis factorrelated apoptosis-inducing ligand R2 and Fas is controlled by $553 .{ }^{22-24}$ Moreover, it was highlighted that $\mathrm{p} 53$ can promote apoptosis in a transcriptional-independent manner. ${ }^{25,26}$ Indeed, after a stress signal, a part of the cytoplasmic pool of p53 is rapidly translocated to mitochondria to increase mitochondrial depolarization and thus cell death. ${ }^{27,28}$ More recently, it has emerged that $\mathrm{p} 53$ is involved in other types of cell death, such as autophagy and necroptosis. ${ }^{29}$

More than 30 years of research on p53 have revealed that this tumor suppressor controls many biological activities, including energy metabolism, cell differentiation, angiogenesis, cell migration, and embryo implantation. ${ }^{30-33}$ In brief, the literature accumulated over the last 34 years indicates that p53-mediated cell responses to damage are diverse because they are adapted (proportionately) to the nature, the extent, and the intensity of the damage, as well as to the cell type and the activated oncogenes (eg, Ras, epidermal growth-factor receptor, estrogen receptor 1). Although p53 is expressed in every cell of our body (except red blood cells), p53 does not impose, regardless of the tissue origin, a universal cell response to a given damage. Cells are of different tissue origin, and thus are composed of very different molecular components (eg, proteins, lipids, chromatin structure), which interact differentially with $\mathrm{p} 53$ and thus constrain $\mathrm{p} 53$ activity. It is essential to take account of the biological constraints of a cell in order to understand why a p53-mediated biological activity is triggered rather than another one.

\section{p53 as a tumor suppressor in cancer}

The p53 protein was first identified in 1979 as a cellular protein overexpressed in simian virus 40-transformed mouse cells and in cancer cells. ${ }^{34,35}$ Given that earlier studies had shown that this protein could promote cell proliferation and transformation, it was initially thought to be an oncogene. ${ }^{36,37}$ 
However, in the late 1980s, different studies have not only revealed that the studied TP53 genes bore missense mutations $^{38,39}$ but also wild-type (WT) p53 protein could inhibit cell transformation induced by an oncogene. ${ }^{40-43}$ TP53 mutations were then highlighted in germ-line cells of patients with the cancer-prone Li-Fraumeni syndrome ${ }^{44,45}$ and in numerous types of cancer cells. Moreover, Donehower et al ${ }^{17}$ have shown that mice deficient in TP53 are susceptible to spontaneous tumorigenesis. As a consequence, TP53 has been characterized as a tumor-suppressor gene, and is now commonly referred to as the "guardian of the genome".

All events that are likely to promote cancer cell formation, such as an abnormal proliferation increase, oncogene activation, DNA damage, or an aberrant cell cycle, lead to an activation of $\mathrm{p} 53$. This tumor suppressor stops damaged cells from proliferating, triggers cell death, and thus prevents cancer formation. Because of its nodal role in integrating extracellular and intracellular signals to maintain cell homeostasis, p53 is inactivated in more than half of all human cancer. ${ }^{46,47}$ It can also be inactivated at the protein level through interaction with viral/cellular proteins, or epigenetic events (hypermethylation) of TP53.48 Many studies have shown that the $\mathrm{p} 53$ pathway can also be inactivated indirectly via an increase of p53 degradation (MDM2 overexpression, PTEN or INK4A/ARF mutation, and deregulation of the Akt pathway, among others), an increased nuclear exclusion, or abnormalities in pathways upstream of p53 (ATM and Chk2 mutation) (Figure 2).

Mutations of TP53 are mostly located in the DNA-binding domain, reducing or completely abolishing the function of the protein. Moreover, in recent years, p53 mutants have shown new properties, named "gain of function", which are different from those of p53 and enhance tumorigenicity. ${ }^{49,50}$ Frequently, TP53 mutation or deletion is associated with chemotherapeutic failure, tumor progression, metastasis, and a shortened overall survival. However, some types of cancer have a low frequency of TP53 mutation or deletion (breast cancer, acute myeloid leukemia [AML], and cervical cancer), and these abnormalities are not always associated with a poor prognosis. Therefore, in those types of cancer, the 553 pathway seems to be disrupted in other ways.

\section{Introduction to the p53 isoforms}

The $\mathrm{p} 53$ protein is encoded by the TP53 gene, which is highly conserved through evolution and is located on the human chromosome $17 \mathrm{p} 13.1$. This gene comprises eleven exons, of which the first is noncoding (Figure 3A), and it contains multiple genetic polymorphisms defining over 100 distinct TP53 haplotypes, some of which have been shown to be correlated with an increased risk of cancer. ${ }^{51-53}$ p53 isoforms were first identified in the late 1980s in humans by Matlashewski et al and in mice by Wolf et al. ${ }^{54,55}$ Thereafter, an alternative splicing of the TP53 gene has been described. ${ }^{56,57}$ Using more sensitive technologies, we and others have shown that the TP53 gene encodes at least twelve different $\mathrm{p} 53$ protein isoforms. ${ }^{56,58,63,64}$ The canonical p53 protein (also named p53, FLp53, p53 $\alpha$, or TAp $53 \alpha$ ) constitutes the most abundant isoform encoded by TP53. This protein of 393 amino acids has seven main functional domains (Figure $3 \mathrm{~B}$ ). The N-terminal transactivation domain is composed of two parts - TAD1 and TAD2 - which were shown to be required to induce a distinct subset of $\mathrm{p} 53$-target genes. The $\mathrm{p} 53$ protein also contains a proline-rich domain (PXXP) and a DNA-binding domain. The $\mathrm{C}$-terminus domain encompasses an oligomerization domain

\section{Mutation of upstream mediators}

\section{ATM $^{*}$, Chk2$^{*} \ldots$}

\section{p19ARF*}

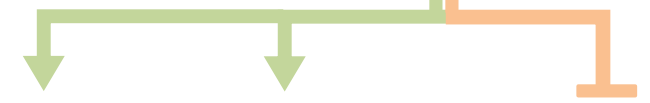

TP53 1-2 3-4-5-6-7-8-9. -10- 11

Mutation, deletion, methylation

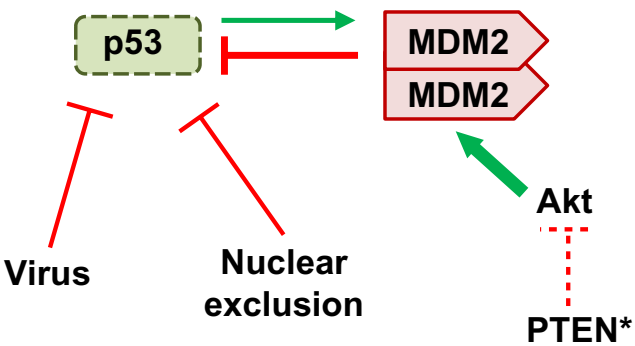

Figure 2 Many ways to inactivate the $\mathrm{p} 53$ pathway in cancer. The $\mathrm{p} 53$ pathway can be inactivated directly by mutation, deletion, or methylation of TP53, or indirectly by mutation $(*)$ of mediators of the $\mathrm{p} 53$ pathway, proteins encoded by viruses, or a nuclear exclusion of $\mathrm{p} 53$.

Abbreviations: ATM, ataxia telangiectasia mutated; MDM2, mouse double minute 2; PTEN, phosphatase and tensin homolog. 
A

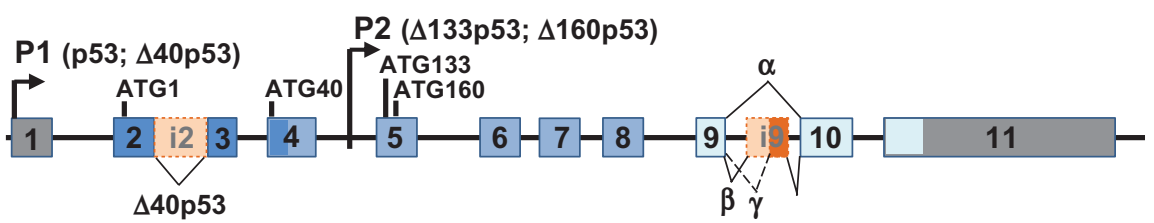

B

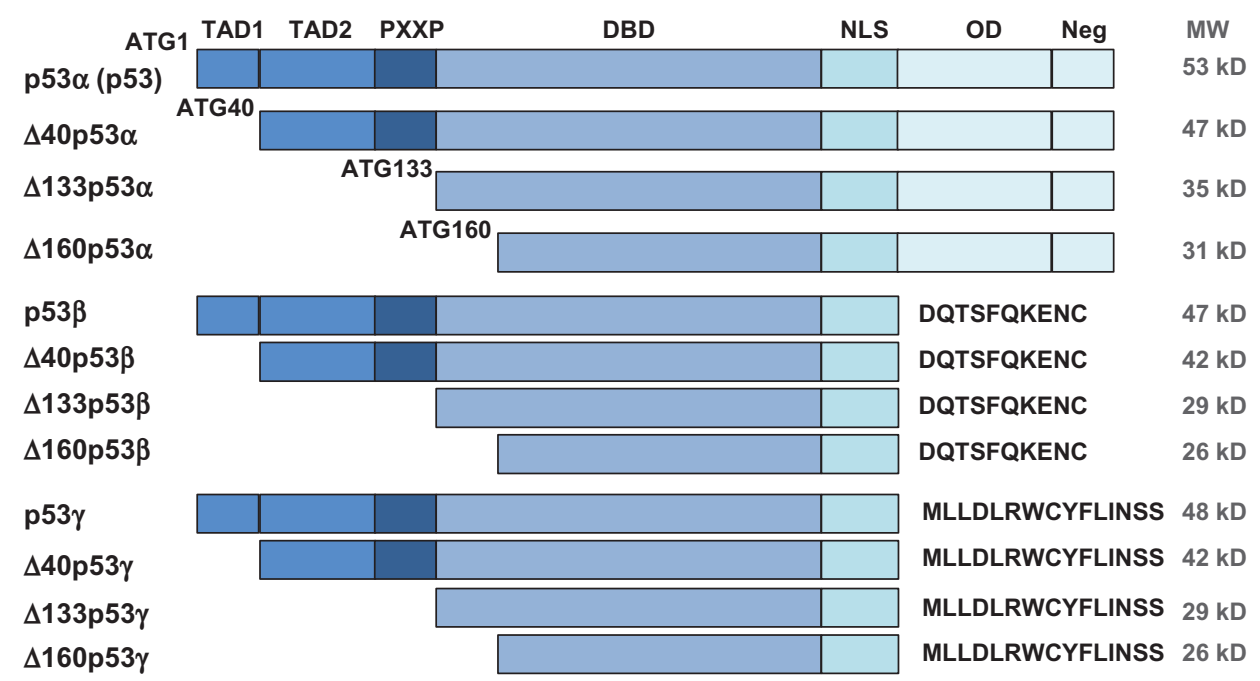

Figure 3 (A and B) The TP53 gene encodes twelve different isoform proteins. (A) The human TP53 gene structure. The TP53 gene comprises eleven exons and encodes several $p 53$ isoforms using alternative promoters $(\neg)$, splicing sites $\left({ }^{\wedge}\right)$, or translational initiation sites $(I)$. (B) Human p53 isoforms. The canonical $p 53(p 53 \alpha)$ has two transactivation domains (TADI aa I-42 and TAD2 aa 43-63), a proline-rich domain (PXXP aa 64-92), a DNA-binding domain (DBD aa I02-306), a nuclear localization domain (NLS aa 316-325), an oligomerization domain (OD aa 307-355), and a negative-regulation domain (Neg aa 364-393).

Abbreviations: $\mathrm{MW}$, molecular weight; $\mathrm{kD}$, kilo Dalton.

(OD) that holds a nuclear localization signaling domain and a negative-regulation domain. The other p53 isoforms are the result of different conserved molecular mechanisms that include alternative splicing, alternative promoter usage, and alternative initiation of translation. Indeed, TP53 contains an internal promoter $(P 2)$ in addition to its proximal promoter (P1). The proximal promoter controls the expression of $\mathrm{p} 53$ (TAp53 $\alpha,-\beta$, and $-\gamma)$ and $\Delta 40 \mathrm{p} 53(\alpha, \beta, \gamma)$, while the internal promoter regulates the expression of $\Delta 133 \mathrm{p} 53(\alpha, \beta, \gamma)$ and $\Delta 160 \mathrm{p} 53(\alpha, \beta, \gamma)$. From these promoters, the twelve p53 isoforms are produced by the use of alternative splicing as well as alternative initiation of translation (Figure 3A).

\section{$p 53 \alpha,-\beta,-\gamma$}

p53 isoforms obtained from the $P 1$ and $P 2$ promoters of the TP53 gene can be classically or alternatively spliced at their $\mathrm{C}$-terminus to produce the $\alpha, \beta$ or $\gamma$ isoforms. Indeed, a complete exclusion of intron 9 of TP53 generates the $\alpha$-form bearing the canonical C-terminal domain with a functional OD, whereas a partial retention of intron 9, also named exon $9 \mathrm{~b}$ and exon $9 \mathrm{~g}$, gives rise to the $\beta$ or the $\gamma$ form, respectively. The entire OD of $\beta$ and $\gamma$ isoforms is replaced by ten and 15 new amino acids, respectively, due to the presence of a stop codon in exon $9 \mathrm{~b}$ and exon $9 \mathrm{~g}$ (Figure 3B). The OD of p53 is very important for the regulation of the protein, as it contains the ubiquitination site for most ubiquitin ligases, such as MDM2, its best-characterized ubiquitin ligase. The molecular mechanisms that control the alternative splicing of intron 9 as well as the degradation of the $\beta$ and $\gamma$ isoforms remain poorly understood.

Contrary to $\mathrm{p} 53$, $\mathrm{p} 53 \beta$ binds preferentially to the proapoptotic Bax promoter, whereas it binds poorly to the $M D M 2$ promoter. In the absence of cellular stress, $p 53 \beta$ can enhance p53 transcriptional activity on the $p 21$ and Bax promoters. p53 $\beta$ can also induce apoptosis in a p53-independent manner, but to a lesser extent than $\mathrm{p} 53 .{ }^{58}$ Furthermore, it has been shown that cotransfection of $\mathrm{p} 53$ and $\mathrm{p} 53 \beta$ induces senescence and enhances p53-mediated apoptosis..$^{59}$ Endogenous $\mathrm{p} 53$ and $\mathrm{p} 53 \beta$ are able to oligomerize and form a protein complex, although it is thought that this complex requires the involvement of other proteins to occur. ${ }^{58}$ Altogether, p53 $\beta$ can regulate p53 tumor-suppressor activity by modulating its transcriptional activity, and thus the selection of target genes regulated. 
p53 $\gamma$ is expressed in normal human tissues. It differs from p53 in that it lacks the last 60 amino acids ( $\alpha$-domain), with the addition of 15 amino acids, which are referred to as the peptide $\gamma$. It localizes to both the nucleus and the cytoplasm. ${ }^{58}$ Contrary to $\mathrm{p} 53 \beta$, it can enhance $\mathrm{p} 53$ transcriptional activity on the Bax promoter, but not on the $p 21$ promoter. $\mathrm{p} 53 \gamma$ can also regulate gene expression independently of $\mathrm{p} 53,{ }^{60}$ and has cytotoxic activity. ${ }^{61}$

\section{$\Delta 40 p 53 \alpha, \Delta 40 p 53 \beta, \Delta 40 p 53 \gamma$}

The $\Delta 40 \mathrm{p} 53$ isoforms (also named p47 or $\Delta \mathrm{Np} 53$ ) are generated by alternative splicing of intron 2 and/or alternative initiation of translation. Indeed, the retention of a part of intron 2 (i2) generates a stop codon between exons 2 and 3 in the p53i2 messenger ribonucleic acid (mRNA) that leads to the initiation of translation at AUG40. Moreover, two internal ribosome entry sites (IRES) have been identified in p53 mRNA, which allow its translation in a cap-independent manner in stress conditions. Consequently, these IRES sequences contribute to the alternative initiation of translation at codon AUG40 instead of AUG1 and therefore to $\Delta 40 \mathrm{p} 53$ expression. ${ }^{62-64}$ Compared to p53, $\Delta 40$ p53 lacks the first 39 amino acids and thus the main transactivation domain of p53 (TAD1), but retains the secondary one (TAD2) (Figure 3B). Little is known about $\Delta 40 \mathrm{p} 53 \alpha,-\beta$ and $-\gamma$, but it has been shown that $\Delta 40 \mathrm{p} 53 \alpha$ has a dominant-negative effect toward p53, inhibits its transcriptional activities, and impairs p53mediated growth suppression. ${ }^{64}$ In addition, $\Delta 40 \mathrm{p} 53 \alpha$ influences p53 ubiquitination and subcellular localization. ${ }^{65}$

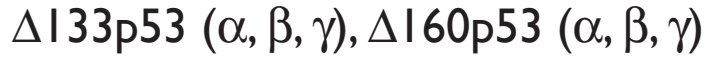

$\Delta 133 \mathrm{p} 53$ and $\Delta 160 \mathrm{p} 53$ isoforms are produced from the internal promoter $(P 2)$ of TP53 in intron 4. Due to alternative initiation of translation, the translation of $\Delta 133 \mathrm{p} 53$ is initiated at codon 133 , while that of $\Delta 160 \mathrm{p} 53$ starts at codon 160 . Therefore, those splice variants lack the two transactivation domains (TAD1 and -2), as well as a part of the DNA-binding domain (Figure 3B).

$\Delta 133$ p53 and $\Delta 160$ p53 isoforms are differentially expressed in normal human tissues. ${ }^{58} \Delta 133 \mathrm{p} 53 \alpha$ is transactivated by p53, p63, and p73 isoforms after genotoxic stress. ${ }^{60,66}$ It modulates gene expression through direct interaction with p53, regulating differentially p53 transcriptional activity in a promoter-dependent manner. ${ }^{59,66,67}$ In addition, $\Delta 133 \mathrm{p} 53 \alpha$ has been shown to regulate gene expression independently of $\mathrm{p} 53(\alpha) .{ }^{60,68}$ Thus, $\Delta 133 \mathrm{p} 53 \alpha$ prevents $\mathrm{p} 53$-mediated replicative senescence, $G_{1}$ cell-cycle arrest (but not $G_{2}$ arrest), and apoptosis by regulating gene expression in a $\mathrm{p} 53(\alpha)$-dependent and -independent manner. $\Delta 133 \mathrm{p} 53 \alpha$ can also promote endothelial cell migration, blood vessel formation, and metastasis formation by regulating expression of angiogenic genes independently of p53. ${ }^{68}$ Altogether, it suggests that $\Delta 133 \mathrm{p} 53 \alpha$ plays an active role in tumor formation and progression. Interestingly, $\Delta 133 \mathrm{p} 53 \alpha$ can promote gastric epithelial cell proliferation and tumorigenesis upon infection by Helicobacter pylori, by directly interacting with p73 isoforms to modulate expression of nuclear factor $\kappa B$ and increased survival of infected cells. ${ }^{69,70}$

Little is known about $\Delta 133 \mathrm{p} 53 \beta$ and $\Delta 133 \mathrm{p} 53 \gamma$, which are expressed in normal human tissue and have different subcellular localization. Their role in cells remains unclear for now. $\Delta 160 \mathrm{p} 53 \alpha, \Delta 160 \mathrm{p} 53 \beta$, and $\Delta 160 \mathrm{p} 53 \gamma$ lack the first 159 amino acids of $\mathrm{p} 53$. It is thought that $\Delta 160 \mathrm{p} 53 \beta$ may have a role in erythroid differentiation. ${ }^{49}$ Of note, this group of isoforms has been found to be expressed in K562 cells, which were previously thought to be "p53-null" cells. ${ }^{71,72}$

Altogether, p53 isoforms can modulate the response to cellular stress either indirectly by regulating transcriptional activity of $\mathrm{p} 53$ family proteins or directly by binding to gene promoters implicated in apoptosis (Bax) or cell-cycle arrest (p21 and miR34a). As a consequence, they can inhibit or enhance p53 tumor-suppressor activity. Nevertheless, it is thought that p53 isoforms have various functional and biological activities that can be p53-independent. ${ }^{73}$

\section{Role of p53 isoforms in human cancer and other pathologies}

It is well established that the tumor-suppressor protein p53 has a major role with regard to the development and progression of cancer, as well as response to chemotherapy. But in numerous clinical studies, it is difficult to predict the clinical outcome and the therapeutic response based on the p53 status. Moreover, in some types of cancer, such as breast cancer or AML, mutation of TP53 is not a frequent event. In fact, as described earlier, the p53 pathway can be inactivated in different manners in cancer. In recent years, given that $\mathrm{p} 53$ isoforms are differentially expressed in tumors compared with normal tissue, their role in carcinogenesis has emerged. ${ }^{74}$

While normal breast tissues express p $53 \alpha$, p53 $\beta$, and $\mathrm{p} 53 \gamma, 60 \%$ of breast tumors have lost the expression of $\mathrm{p} 53 \beta$ and $\mathrm{p} 53 \gamma$. Moreover, among these, $40 \%$ overexpress the isoform $\Delta 133 \mathrm{p} 53 .{ }^{75}$ Regarding melanoma, it has been shown that the isoforms p53 $\beta$ and $\Delta 40 \mathrm{p} 53$ are expressed in tumor cells but not in melanocytes or fibroblasts. ${ }^{76}$ In renal cell carcinoma (RCC), p53 $\beta$ and $\Delta 133$ p53 isoforms are overexpressed in 
tumor cells compared with normal cells. ${ }^{77}$ Other studies have shown that p53 isoforms are also abnormally expressed in AML, cholangiocarcinoma, glioblastoma, head and neck tumors, colon carcinoma, and ovarian and lung tumors, ${ }^{78-83}$ and it can be expected that numerous other types of cancer are concerned.

It has been described that some pathogens could modulate p53 isoform expression. ${ }^{84}$ Indeed, it is well known that the canonical $\mathrm{p} 53$ protein $(\mathrm{p} 53 \alpha$ ) can be inactivated by viral proteins. ${ }^{85,86}$ Moreover, it has been shown that the pathogenic bacteria $H$. pylori interacts with gastric epithelial cells and induces the expression of amino-terminally truncated $\Delta 133$ p53 and $\Delta 160 p 53$ variants, thus increasing cell survival and possibly allowing cancer to develop. ${ }^{69}$ On the other hand, polymorphism or mutations in the noncoding region of the TP53 gene can affect the expression of isoforms. Indeed, a mutation in the IRES sequence, introns, or in splice sites can either abrogate the expression of certain isoforms or induce the transcription of tumor-specific p53 mRNA. ${ }^{78,87,88}$

As described earlier, p53 isoforms have the ability to switch $\mathrm{p} 53$ activity between $\mathrm{p} 53$-mediated prosurvival activity and p53-mediated cell death (Figure 4). Consequently, when they are abnormally expressed, they can be a factor for cancer development and progression as well as chemotherapy sensitivity. From these results, several mouse models were developed to investigate the role of some p53 isoforms in cancer and other pathologies.

Slatter et $\mathrm{al}^{70}$ have generated a mouse expressing a mutant of $\mathrm{p} 53$ deleted of the first 122 amino acids $(\Delta 122 \mathrm{p} 53)$ in order to mimic human $\Delta 133 \mathrm{p} 53$. However, contrary to human $\Delta 133$ p 53 , mouse $\Delta 122$ p53 mutant expression is not driven by the endogenous p53 internal promoter. Therefore, $\Delta 122 \mathrm{p} 53$ is not expressed in a tissue-dependent manner, and thus does not exactly recapitulate the roles of human $\Delta 133 \mathrm{p} 53$ in cancer formation. Despite this limitation, the $\Delta 122 \mathrm{p} 53$ mouse model is useful, because it demonstrated that mutant $\Delta 122 \mathrm{p} 53$ protein is active in promoting hyperproliferation and cancer development, despite having lost both transactivation domains and part of the DNA-binding domain. In addition, $\Delta 122$ p53 mice show a profound proinflammatory phenotype having increased serum concentrations of interleukin 6 and other proinflammatory cytokines, with aggregation of lymphocytes in the lung and liver. Therefore, $\Delta 133 \mathrm{p} 53$ may promote cell proliferation and inflammation, contributing to tumor development.

This is consistent with recent publications on gerbils demonstrating that endogenous $\Delta 153 \mathrm{p} 53$ isoforms, homologous to human $\Delta 133 \mathrm{p} 53 / \Delta 160 \mathrm{p} 53$, are induced upon infection by $H$. pylori, promoting gastric epithelial cell proliferation, cytokine expression, and tumorigenesis formation. ${ }^{69,70}$ Furthermore, Bernard et $\mathrm{al}^{68}$ have demonstrated in a mouse xenograft model and chick chorioallantoic membrane assay that $\Delta 133 \mathrm{p} 53 \alpha$ could stimulate cell migration, angiogenesis, and thus cancer progression by regulating angiogenic gene expression. Altogether, this confirms that $\Delta 133 \mathrm{p} 53 \alpha$ is an active protein that has an important biological relevance.

By comparing $\Delta 122 \mathrm{p} 53$ and $\Delta 40 \mathrm{p} 53$ mouse models, it appears that $\Delta 122 \mathrm{p} 53$ and $\Delta 40 \mathrm{p} 53$ have different biological

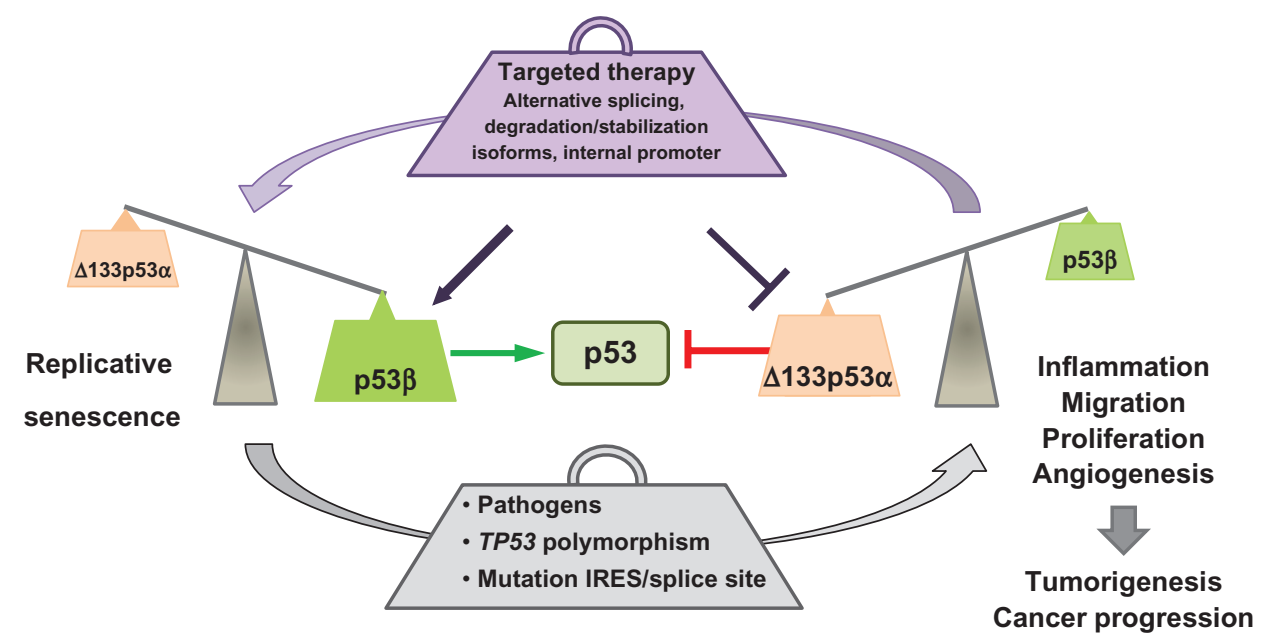

Figure 4 p53 isoforms in cancer and targeted therapy. Depending on the cell context, some $p 53$ isoforms, such as $\Delta / 33 p 53 \alpha$, inhibit the antitumor role of the canonical $\mathrm{p} 53 \alpha$, while others potentiate its activity. In cancer, the imbalance between the $\mathrm{p} 53$ isoforms can promote a prosurvival effect, and thus allows cancer cells to survive. The prosurvival phenotype of these cells can be changed toward the proapoptotic phenotype by altering the p53 isoform-expression profile. Using small molecules targeting the alternative splicing of p53, protein degradation, or p53 internal promoter activity, it could be possible to decrease expression of antiapoptotic isoforms, or on the contrary to increase proapoptotic isoform expression.

Abbreviations: IRES, internal ribosome entry site. 
activities and are thus not equivalent. While overexpression of $\Delta 122 \mathrm{p} 53$ or induction of endogenous $\Delta 153 \mathrm{p} 53$ by $H$. pylori induces cancer, overexpression of transgenic $\Delta 40 \mathrm{p} 53$ in mice expressing WT TP53 alleles induces premature ageing and diabetes, but not cancer. ${ }^{89-93}$ This is consistent with a role of $\triangle 40$ p53 in regulating cell stemness. ${ }^{91}$

This suggests that $\mathrm{p} 53$ isoforms have roles in pathologies other than cancer. Indeed, we recently reported that $\mathrm{p} 53$ isoforms are also differentially regulated in response to flu virus infection and play an active role in regulating flu virus production. ${ }^{84,94-96}$

\section{Overview of the clinical implications of p53 isoform activity in cancer}

Numerous clinical studies have demonstrated that the expression profile of $\mathrm{p} 53$ isoforms can be linked with tumor progression, clinical response, and/or prognosis. Contrary to $\mathrm{p} 53 \beta$, which promotes replicative senescence, $\Delta 133 \mathrm{p} 53 \alpha$ promotes proliferation and senescence escape (Figure 4). As a consequence, Fujita et al ${ }^{15}$ have described that an inversion of the $p 53 \beta / \Delta 133 p 53 \alpha$ ratio (a decrease of $p 53 \beta$ expression associated with an increase of $\Delta 133 \mathrm{p} 53 \alpha$ expression) could allow cancer progression from colorectal adenoma to carcinoma. In RCC, p $53 \beta$ overexpression in tumors is related to tumor stages, and could be a good predictor of cancer progression. ${ }^{77}$ Regarding mucinous ovarian cancer, Hofstetter et al have shown that $\mathrm{p} 53 \beta$ and $\Delta 133 \mathrm{p} 53$ are abnormally expressed. In addition, the expression of $\Delta 40 \mathrm{p} 53 \alpha$ in WT 553 ovarian cancer was associated with an improved recurrence-free survival. ${ }^{97}$ Importantly, in serous ovarian cancer, it was reported that $\Delta 133 p 53 \alpha$ expression was associated with higher disease-free survival and overall survival in p53 mutant advanced serous ovarian carcinoma cancer cases, while $\Delta 40 \mathrm{p} 53 \alpha$ was associated with higher disease-free survival and overall survival in WT p53 advanced serous ovarian carcinoma patients. ${ }^{98}$ This suggests that $\mathrm{p} 53$ mutation status can affect the prognostic value of $\mathrm{p} 53$ isoforms. In addition, $\mathrm{p} 53 \beta$ expression was associated with adverse clinicopathologic markers, such as serous and poorly differentiated cancers, and was associated with worse recurrence-free survival in patients exhibiting functionally active p53. ${ }^{78}$ Moreover, the expression of a tumor-specific splice-site mutant p53 mRNA (p538) is associated with therapeutic failure and thus a poor prognosis. ${ }^{78} \mathrm{In}$ breast cancer, determination of $\mathrm{p} 53 \gamma$ isoform expression in p53 mutant breast cancer patients allows the identification of the ones with a particularly poor prognosis. Indeed, mutant p53 breast patients expressing p53 $\gamma$ have as good a prognosis as WT p53 breast cancer patients, while mutant p53 breast cancer patients not expressing $\mathrm{p} 53 \gamma$ have a particularly poor prognosis, and would benefit from additional treatment. ${ }^{75} \mathrm{In}$ cholangiocarcinoma, $\Delta 133 \mathrm{p} 53$ overexpression is associated with a shortened overall survival.$^{83}$ In acute myeloid leukemia, determination of $\mathrm{p} 53$ isoform expression revealed distinct $\mathrm{p} 53$ protein biosignatures correlating with clinical outcome. ${ }^{81,99}$

As $\mathrm{p} 53$ isoforms modulate $\mathrm{p} 53$ tumor-suppressor activity and gene expression, it is expected that their overexpression or loss of expression in cancer is associated with carcinogenesis. However, in some cases, they could represent an alternative way to abrogate gain of function of mutant $\mathrm{p} 53$ in cancers. For example, $\Delta 133 \mathrm{p} 53$ overexpression in mutant p53 ovarian cancer or $\mathrm{p} 53 \gamma$ expression in mutant $\mathrm{p} 53$ breast cancer overcomes the adverse impact of TP53 mutation. ${ }^{75,98}$

A new therapeutic strategy currently in development consists in the reactivation of $\mathrm{p} 53$ in cancer cells by reactivating mutant $\mathrm{p} 53$ protein or by inhibiting $\mathrm{p} 53$ repressors, such as MDM2. ${ }^{100,101}$ The uncovering of $\mathrm{p} 53$ isoforms enlarges this research field. Moreover, based on the observation that aberrant p53 isoform expression is associated with cancer development and progression, it can be assumed that they could become tumor markers and efficient targets for cancer therapy.

It is well known that different cellular stresses, such as DNA damage, change the mRNA-splicing process. ${ }^{102}$ Indeed, several studies have already shown that expression of p53 isoforms can be modulated in vivo in response to chemotherapy. ${ }^{76,81}$ These changes of splicing can be correlated with an increase of sensitivity, or on the contrary generate chemoresistance. From these observations, it is expected that the identification of splicing factors or IREStransacting factors involved in isoform expression will allow defining novel therapeutic targets and new treatments. Some regulators of p53 isoforms have already been identified, such as the IRES transacting factors polypyrimidine tractbinding protein (PTB), dyskerin, death-associated protein 5 (DAP5), annexin A2, and PTB-associated splicing factor (PSF). ${ }^{103-106}$ Treatments targeting these factors and thus isoform expression could reverse the adverse effect of an elevated $\Delta 133 \mathrm{p} 53 \alpha / \mathrm{p} 53 \beta$ ratio in order to stop proliferation and cancer progression (Figure 4). In addition, it is possible to manipulate p53 isoform expression by regulating their protein-degradation pathway. The entire ubiquitinase network of p53 family proteins is not known yet, but it has been shown that p53 isoforms are differently affected by the main E3 ligase of $\mathrm{p} 53 \alpha-\mathrm{MDM} 2 .{ }^{107}$ The MDM2 antagonist nutlin-3a has already been shown to be effective in stabilizing p $53 \alpha$ to sensitize cells to chemotherapy. ${ }^{101,108}$ The identification of 
other ubiquitin ligases involved in p53 isoform degradation could allow the design of new targeted therapies.

\section{Conclusion}

Since the discovery of p53 more than 30 years ago, the need to acquire more knowledge about this protein has constantly increased, given its prominent role in cancer. p53 is involved in many physiological processes, the most studied being its tumor-suppressor function. p53 integrates much cell signaling from damaged internal subcellular organelles, as well as cellcell contact, extracellular matrix, hormones, cytokines, and nutrient level. Based on these signals, p53 contributes to the cell-fate decision to trigger cell survival, senescence, differentiation, cell migration, or programmed cell death. However, the underlying molecular mechanisms are still unclear. Owing to various technical advances in biochemistry and genetics, different studies have highlighted that the TP53 gene encodes several p53 protein isoforms, which cooperate with p53 and modulate its activity toward either promoting cell survival or death. Given that p53 isoforms play a fundamental role in the regulation of the p53 pathway, their expression is often deregulated in cancer. One could therefore wonder whether WT TP53 can act as a tumor-suppressor gene or oncogene, depending on the p53 isoform-expression profile. In some cancer types, abnormal p53 isoform expression has been correlated with clinical response, cancer recurrence, and/or overall survival. Moreover, certain isoforms seem to be potential markers for cancer therapy. However, p53 isoforms cannot be categorized into oncogenic or tumor-suppressor classes, since their biological activities and thus their prognostic value are associated with the cell context. Indeed, $\Delta 133 \mathrm{p} 53 \alpha$ expression is associated with cancer formation and progression in cholangiocarcinoma, as well as in colon and gastric cancers, while $\Delta 133 p 53 \alpha$ is associated with a lower risk of cancer recurrence and death in mutant $\mathrm{p} 53$ serous ovarian cancer. Similarly, p $53 \beta$ is associated with clinicopathological markers of good prognosis in colon cancer and AML, while p $53 \beta$ is associated with worse recurrence-free survival in serous ovarian cancer patients exhibiting functionally active p53.

Further clinical studies will be necessary to develop a deeper understanding of their involvement in cancer. On the other hand, research on molecules that "reactivate" the p53 pathway in tumor cells appears to be a promising way as long as the cell context is taken into account. It is expected that some p53 isoforms will be good therapeutic targets in defined cancer subtypes, such as luminal or triple-negative breast cancer. To achieve this, future experiments will focus on defining the cell contexts that constrain WT or mutated p53 isoforms to promote cell survival or cell death in response to a given damage or treatment. The results will allow better understanding as to how p53 isoform expression is regulated, thus enabling the design of efficient treatments.

\section{Acknowledgments}

Sylvanie Surget was supported by Fondation pour la Recherche Médicale. Marie P Khoury was supported by Cancer Research UK, and Jean-Christophe Bourdon is a Research Fellow of Breast Cancer Campaign.

\section{Disclosure}

The authors report no conflicts of interest in this work.

\section{References}

1. Bénard J, Douc-Rasy S, Ahomadegbe JC. TP53 family members and human cancers. Hum Mutat. 2003;21(3):182-191.

2. Melino G, Lu X, Gasco M, Crook T, Knight RA. Functional regulation of p73 and p63: development and cancer. Trends Biochem Sci. 2003;28(12):663-670.

3. Flores ER, Sengupta S, Miller JB, et al. Tumor predisposition in mice mutant for $\mathrm{p} 63$ and $\mathrm{p} 73$ : evidence for broader tumor suppressor functions for the p53 family. Cancer Cell. 2005;7(4):363-373.

4. Khoury MP, Bourdon JC. p53 Isoforms: an intracellular microprocessor? Genes Cancer. 2011;2(4):453-465.

5. Kaghad M, Bonnet H, Yang A, et al. Monoallelically expressed gene related to p53 at $1 \mathrm{p} 36$, a region frequently deleted in neuroblastoma and other human cancers. Cell. 1997;90(4):809-819.

6. Yang A, Kaghad M, Wang Y, et al. p63, A p53 homolog at 3q27-29, encodes multiple products with transactivating, death-inducing, and dominant-negative activities. Mol Cell. 1998;2(3):305-316.

7. Ding Y, Inoue T, Kamiyama J, et al. Molecular cloning and functional characterization of the upstream promoter region of the human p73 gene. DNA Res. 1999;6(5):347-351.

8. Murray-Zmijewski F, Lane DP, Bourdon JC. p53/p63/p73 Isoforms: an orchestra of isoforms to harmonise cell differentiation and response to stress. Cell Death Differ. 2006;13(6):962-972.

9. Dötsch V, Bernassola F, Coutandin D, Candi E, Melino G. p63 And p73, the ancestors of p53. Cold Spring Harb Perspect Biol. 2010;2(9):a004887.

10. Oren M. Decision making by p53: life, death and cancer. Cell Death Differ. 2003;10(4):431-442.

11. Meek DW, Anderson CW. Posttranslational modification of p53: cooperative integrators of function. Cold Spring Harb Perspect Biol. 2009;1(6):a000950.

12. Honda R, Tanaka H, Yasuda H. Oncoprotein MDM2 is a ubiquitin ligase E3 for tumor suppressor p53. FEBS Lett. 1997;420(1):25-27.

13. Leng RP, Lin Y, Ma W, et al. Pirh2, a p53-induced ubiquitin-protein ligase, promotes p53 degradation. Cell. 2003;112(6):779-791.

14. el-Deiry WS, Kern SE, Pietenpol JA, Kinzler KW, Vogelstein B. Definition of a consensus binding site for p53. Nat Genet. 1992;1(1):45-49.

15. Funk WD, Pak DT, Karas RH, Wright WE, Shay JW. A transcriptionally active DNA-binding site for human p53 protein complexes. Mol Cell Biol. 1992;12(6):2866-2871.

16. Li M, He Y, Dubois W, Wu X, Shi J, Huang J. Distinct regulatory mechanisms and functions for p53-activated and p53-repressed DNA damage response genes in embryonic stem cells. Mol Cell. 2012;46(1): 30-42.

17. Donehower LA, Harvey M, Slagle BL, et al. Mice deficient for p53 are developmentally normal but susceptible to spontaneous tumours. Nature. 1992;356(6366):215-221. 
18. Hall PA, McKee PH, Menage HD, Dover R, Lane DP. High levels of p53 protein in UV-irradiated normal human skin. Oncogene. 1993;8(1): 203-207.

19. Taylor WR, Stark GR. Regulation of the G2/M transition by p53. Oncogene. 2001;20(15):1803-1815.

20. Sperka T, Wang J, Rudolph KL. DNA damage checkpoints in stem cells, ageing and cancer. Nat Rev Mol Cell Biol. 2012;13(9):579-590.

21. Kuribayashi K, El-Deiry WS. Regulation of programmed cell death by the p53 pathway. Adv Exp Med Biol. 2008;615:201-221.

22. Wu GS, Burns TF, McDonald ER 3rd, et al. KILLER/DR5 is a DNA damage-inducible p53-regulated death receptor gene. Nat Genet. 1997;17(2):141-143.

23. Sheikh MS, Burns TF, Huang Y, et al. p53-Dependent and -independent regulation of the death receptor KILLER/DR5 gene expression in response to genotoxic stress and tumor necrosis factor alpha. Cancer Res. 1998;58(8):1593-1598.

24. Owen-Schaub LB, Zhang W, Cusack JC, et al. Wild-type human p53 and a temperature-sensitive mutant induce Fas/APO-1 expression. Mol Cell Biol. 1995;15(6):3032-3040.

25. Caelles C, Helmberg A, Karin M. p53-Dependent apoptosis in the absence of transcriptional activation of p53-target genes. Nature. 1994;370(6486):220-223.

26. Moll UM, Wolff S, Speidel D, Deppert W. Transcription-independent pro-apoptotic functions of p53. Curr Opin Cell Biol. 2005;17(6): 631-636.

27. Marchenko ND, Zaika A, Moll UM. Death signal-induced localization of $\mathrm{p} 53$ protein to mitochondria. A potential role in apoptotic signaling. J Biol Chem. 2000;275(21):16202-16212.

28. Mihara M, Erster S, Zaika A, et al. p53 Has a direct apoptogenic role at the mitochondria. Mol Cell. 2003;11(3):577-590.

29. Crighton D, Wilkinson S, O'Prey J, et al. DRAM, a p53-induced modulator of autophagy, is critical for apoptosis. Cell. 2006;126(1):121-134.

30. Maddocks OD, Vousden KH. Metabolic regulation by p53. J Mol Med (Berl). 2011;89(3):237-245.

31. Pant V, Quintás-Cardama A, Lozano G. The p53 pathway in hematopoiesis: lessons from mouse models, implications for humans. Blood. 2012;120(26):5118-5127.

32. Quadrato G, Di Giovanni S. Gatekeeper between quiescence and differentiation: p53 in axonal outgrowth and neurogenesis. Int Rev Neurobiol. 2012;105:71-89.

33. Levine AJ, Tomasini R, McKeon FD, Mak TW, Melino G. The p53 family: guardians of maternal reproduction. Nat Rev Mol Cell Biol. 2011;12(4):259-265.

34. Lane DP, Crawford LV. T antigen is bound to a host protein in SV40transformed cells. Nature. 1979;278(5701):261-263.

35. Linzer DI, Levine AJ. Characterization of a $54 \mathrm{~K}$ dalton cellular SV40 tumor antigen present in SV40-transformed cells and uninfected embryonal carcinoma cells. Cell. 1979;17(1):43-52.

36. Reich NC, Levine AJ. Growth regulation of a cellular tumour antigen, p53, in nontransformed cells. Nature. 1984;308(5955):199-201.

37. Mercer WE, Avignolo C, Baserga R. Role of the $\mathrm{p} 53$ protein in cell proliferation as studied by microinjection of monoclonal antibodies. Mol Cell Biol. 1984;4(2):276-281.

38. Mowat M, Cheng A, Kimura N, Bernstein A, Benchimol S Rearrangements of the cellular p53 gene in erythroleukaemic cells transformed by Friend virus. Nature. 1985;314(6012):633-636.

39. Munroe DG, Rovinski B, Bernstein A, Benchimol S. Loss of a highly conserved domain on p53 as a result of gene deletion during Friend virus-induced erythroleukemia. Oncogene. 1988;2(6):621-624.

40. Hinds P, Finlay C, Levine AJ. Mutation is required to activate the p53 gene for cooperation with the ras oncogene and transformation. J Virol. 1989;63(2):739-746.

41. Finlay CA, Hinds PW, Levine AJ. The p53 proto-oncogene can act as a suppressor of transformation. Cell. 1989;57(7):1083-1093.

42. Eliyahu D, Michalovitz D, Eliyahu S, Pinhasi-Kimhi O, Oren M. Wild-type p53 can inhibit oncogene-mediated focus formation. Proc Natl Acad Sci U S A. 1989;86(22):8763-8767.
43. Jenkins JR, Rudge K, Currie GA. Cellular immortalization by a cDNA clone encoding the transformation-associated phosphoprotein $\mathrm{p} 53$. Nature. 1984;312(5995):651-654.

44. Malkin D, Li FP, Strong LC, et al. Germ line p 53 mutations in a familial syndrome of breast cancer, sarcomas, and other neoplasms. Science. 1990;250(4985):1233-1238.

45. Srivastava S, Zou ZQ, Pirollo K, Blattner W, Chang EH. Germ-line transmission of a mutated p53 gene in a cancer-prone family with Li-Fraumeni syndrome. Nature. 1990;348(6303):747-749.

46. Levine AJ, Momand J, Finlay CA. The p53 tumour suppressor gene. Nature. 1991;351(6326):453-456.

47. Hollstein M, Sidransky D, Vogelstein B, Harris CC. p53 mutations in human cancers. Science. 1991;253(5015):49-53.

48. Levine AJ. The common mechanisms of transformation by the small DNA tumor viruses: the inactivation of tumor suppressor gene products: p53. Virology. 2009;384(2):285-293.

49. Goldstein I, Marcel V, Olivier M, Oren M, Rotter V, Hainaut P. Understanding wild-type and mutant p53 activities in human cancer: new landmarks on the way to targeted therapies. Cancer Gene Ther. 2011;18(1):2-11.

50. Freed-Pastor WA, Prives C. Mutant p53: one name, many proteins. Genes Dev. 2012;26(12):1268-1286.

51. Dumont P, Leu JI, Della Pietra AC 3rd, George DL, Murphy M. The codon 72 polymorphic variants of $\mathrm{p} 53$ have markedly different apoptotic potential. Nat Genet. 2003;33(3):357-365.

52. Garritano S, Gemignani F, Palmero EI, et al. Detailed haplotype analysis at the TP53 locus in p.R337H mutation carriers in the population of Southern Brazil: evidence for a founder effect. Hum Mutat. 2010;31(2): $143-150$.

53. Wu D, Zhang Z, Chu H, Xu M, Xue Y, Zhu H. Intron 3 sixteen base pairs duplication polymorphism of $\mathrm{p} 53$ contributes to breast cancer susceptibility: evidence from meta-analysis. PLoS One. 2013;8(4):e61662.

54. Matlashewski G, Lamb P, Pim D, Peacock J, Crawford L, Benchimol S. Isolation and characterization of a human $\mathrm{p} 53 \mathrm{cDNA}$ clone: expression of the human p53 gene. EMBO J. 1984;3(13):3257-3262.

55. Wolf D, Harris N, Goldfinger N, Rotter V. Isolation of a fulllength mouse cDNA clone coding for an immunologically distinct p53 molecule. Mol Cell Biol. 1985;5(1):127-132.

56. Flaman JM, Waridel F, Estreicher A, et al. The human tumour suppressor gene p53 is alternatively spliced in normal cells. Oncogene. 1996;12(4):813-818.

57. Arai N, Nomura D, Yokota K, et al. Immunologically distinct p53 molecules generated by alternative splicing. Mol Cell Biol. 1986;6(9): 3232-3239.

58. Bourdon JC, Fernandes K, Murray-Zmijewski F, et al. p53 Isoforms can regulate p53 transcriptional activity. Genes Dev. 2005;19(18): 2122-2137.

59. Fujita K, Mondal AM, Horikawa I, et al. p53 Isoforms Delta133p53 and p53beta are endogenous regulators of replicative cellular senescence. Nat Cell Biol. 2009;11(9):1135-1142.

60. Marcel V, Petit I, Murray-Zmijewski F, et al. Diverse p63 and p73 isoforms regulate Delta133p53 expression through modulation of the internal TP53 promoter activity. Cell Death Differ. 2012;19(5):816-826.

61. Silden E, Hjelle SM, Wergeland L, et al. Expression of TP53 isoforms p53beta or p53gamma enhances chemosensitivity in TP53(null) cell lines. PLoS One. 2013;8(2):e56276.

62. Ray PS, Grover R, Das S. Two internal ribosome entry sites mediate the translation of p53 isoforms. EMBO Rep. 2006;7(4):404-410.

63. Yin Y, Stephen CW, Luciani MG, Fahraeus R. p53 Stability and activity is regulated by $\mathrm{Mdm} 2$-mediated induction of alternative $\mathrm{p} 53$ translation products. Nat Cell Biol. 2002;4(6):462-467.

64. Courtois S, Verhaegh G, North S, et al. DeltaN-p53, a natural isoform of p53 lacking the first transactivation domain, counteracts growth suppression by wild-type p53. Oncogene. 2002;21(44):6722-6728.

65. Ghosh A, Stewart D, Matlashewski G. Regulation of human $\mathrm{p} 53$ activity and cell localization by alternative splicing. Mol Cell Biol. 2004;24(18): 7987-7997. 
66. Aoubala M, Murray-Zmijewski F, Khoury MP, et al. p53 Directly transactivates Delta133p53alpha, regulating cell fate outcome in response to DNA damage. Cell Death Differ. 2011;18(2):248-258.

67. Marcel V, Vijayakumar V, Fernández-Cuesta L, et al. p53 Regulates the transcription of its Delta133p53 isoform through specific response elements contained within the TP53 P2 internal promoter. Oncogene. 2010;29(18):2691-2700

68. Bernard H, Garmy-Susini B, Ainaoui N, et al. The p53 isoform, Delta133p53alpha, stimulates angiogenesis and tumour progression. Oncogene. 2013;32(17):2150-2160.

69. Wei J, Noto J, Zaika E, et al. Pathogenic bacterium Helicobacter pylori alters the expression profile of $\mathrm{p} 53$ protein isoforms and $\mathrm{p} 53$ response to cellular stresses. Proc Natl Acad Sci U S A. 2012;109(38): E2543-E2550.

70. Slatter TL, Hung N, Campbell H, et al. Hyperproliferation, cancer, and inflammation in mice expressing a Delta133p53-like isoform. Blood. 2011;117(19):5166-5177.

71. Neubauer A, He M, Schmidt CA, Huhn D, Liu ET. Genetic alterations in the p53 gene in the blast crisis of chronic myelogenous leukemia analysis by polymerase chain reaction based techniques. Leukemia. 1993;7(4):593-600.

72. Marcel V, Perrier S, Aoubala M, et al. Delta160p53 is a novel $\mathrm{N}$-terminal $\mathrm{p} 53$ isoform encoded by Delta133p 53 transcript. FEBS Lett. 2010;584(21):4463-4468.

73. Rohaly G, Chemnitz J, Dehde S, et al. A novel human p53 isoform is an essential element of the ATR-intra-S phase checkpoint. Cell. 2005;122(1):21-32.

74. Khoury MP, Bourdon JC. The isoforms of the $\mathrm{p} 53$ protein. Cold Spring Harb Perspect Biol. 2010;2(3):a000927.

75. Bourdon JC, Khoury MP, Diot A, et al. p53 Mutant breast cancer patients expressing p53 gamma have as good a prognosis as wild-type p53 breast cancer patients. Breast Cancer Res. 2011;13(1):R7.

76. Avery-Kiejda KA, Zhang XD, Adams LJ, et al. Small molecular weight variants of p53 are expressed in human melanoma cells and are induced by the DNA-damaging agent cisplatin. Clin Cancer Res. 2008;14(6):1659-1668.

77. Song W, Huo SW, Lu JJ, et al. Expression of p53 isoforms in renal cell carcinoma. Chin Med J (Engl). 2009;122(8):921-926.

78. Hofstetter G, Berger A, Fiegl H, et al. Alternative splicing of p53 and p73: the novel $\mathrm{p} 53$ splice variant $\mathrm{p} 53$ delta is an independent prognostic marker in ovarian cancer. Oncogene. 2010;29(13):1997-2004.

79. Marabese M, Marchini S, Marrazzo E, et al. Expression levels of p53 and p73 isoforms in stage I and stage III ovarian cancer. Eur J Cancer. 2008;44(1):131-141.

80. Boldrup L, Bourdon JC, Coates PJ, Sjöström B, Nylander K. Expression of p53 isoforms in squamous cell carcinoma of the head and neck. Eur J Cancer. 2007;43(3):617-623.

81. Anensen N, Oyan AM, Bourdon JC, Kalland KH, Bruserud O, Gjertsen BT. A distinct $\mathrm{p} 53$ protein isoform signature reflects the onset of induction chemotherapy for acute myeloid leukemia. Clin Cancer Res. 2006;12(13):3985-3992.

82. Takahashi R, Giannini C, Sarkaria JN, et al. p53 Isoform profiling in glioblastoma and injured brain. Oncogene. 2013;32(26): 3165-3174.

83. Nutthasirikul N, Limpaiboon T, Leelayuwat C, Patrakitkomjorn S, Jearanaikoon P. Ratio disruption of the 133p53 and TAp53 isoform equilibrium correlates with poor clinical outcome in intrahepatic cholangiocarcinoma. Int J Oncol. 2013;42(4):1181-1188.

84. Terrier O, Bourdon JC, Rosa-Calatrava M. p53 Protein isoforms: key regulators in the front line of pathogen infections? PLoS Pathog. 2013;9(4):e1003246

85. Collot-Teixeira S, Bass J, Denis F, Ranger-Rogez S. Human tumor suppressor p53 and DNA viruses. Rev Med Virol. 2004;14(5): 301-319.

86. Soria C, Estermann FE, Espantman KC, O'Shea CC. Heterochromatin silencing of p53 target genes by a small viral protein. Nature. 2010;466(7310):1076-1081.
87. Grover R, Sharathchandra A, Ponnuswamy A, Khan D, Das S. Effect of mutations on the p53 IRES RNA structure: implications for deregulation of the synthesis of p53 isoforms. RNA Biol. 2011;8(1): 132-142.

88. Khan D, Sharathchandra A, Ponnuswamy A, Grover R, Das S. Effect of a natural mutation in the $5^{\prime}$ untranslated region on the translational control of p53 mRNA. Oncogene. 2013;32(35):4148-4159.

89. Franck D, Tracy L, Armata HL, et al. Glucose tolerance in mice is linked to the dose of the p53 transactivation domain. Endocr Res. Epub October 26, 2012.

90. Hinault C, Kawamori D, Liew CW, et al. Delta40 isoform of p53 controls beta-cell proliferation and glucose homeostasis in mice. Diabetes. 2011;60(4):1210-1222.

91. Ungewitter E, Scrable H. Delta40p53 controls the switch from pluripotency to differentiation by regulating IGF signaling in ESCs. Genes Dev. 2010;24(21):2408-2419.

92. Pehar M, O'Riordan KJ, Burns-Cusato M, et al. Altered longevityassurance activity of p53:p44 in the mouse causes memory loss, neurodegeneration and premature death. Aging Cell. 2010;9(2): 174-190.

93. Maier B, Gluba W, Bernier B, et al. Modulation of mammalian life span by the short isoform of p53. Genes Dev. 2004;18(3):306-319.

94. Terrier O, Diederichs A, Dubois J, et al. Influenza NS1 interacts with p53 and alters its binding to p53-responsive genes, in a promoterdependent manner. FEBS Lett. 2013;587(18):2965-2971.

95. Terrier $\mathrm{O}$, Marcel $\mathrm{V}$, Cartet $\mathrm{G}$, et al. Influenza A viruses control expression of proviral human p53 isoforms p53beta and Delta133p53alpha. $J$ Virol. 2012;86(16):8452-8460.

96. Terrier O, Textoris J, Carron C, Marcel V, Bourdon JC, Rosa-Calatrava M. Host microRNA molecular signatures associated with human H1N1 and $\mathrm{H} 3 \mathrm{~N} 2$ influenza $\mathrm{A}$ viruses reveal an unanticipated antiviral activity for miR-146a. J Gen Virol. 2013;94(Pt 5):985-995.

97. Hofstetter G, Berger A, Berger R, et al. The N-terminally truncated p53 isoform Delta40p53 influences prognosis in mucinous ovarian cancer. Int J Gynecol Cancer. Mar 2012;22(3):372-379.

98. Hofstetter G, Berger A, Schuster E, et al. Delta133p53 is an independent prognostic marker in $\mathrm{p} 53$ mutant advanced serous ovarian cancer. Br J Cancer. 2011;105(10):1593-1599.

99. Anensen N, Hjelle SM, Van Belle W, et al. Correlation analysis of p53 protein isoforms with NPM1/FLT3 mutations and therapy response in acute myeloid leukemia. Oncogene. 2012;31(12):1533-1545.

100. Selivanova G, Wiman KG. Reactivation of mutant p53: molecular mechanisms and therapeutic potential. Oncogene. 2007;26(15): 2243-2254.

101. Vassilev LT, Vu BT, Graves B, et al. In vivo activation of the p53 pathway by small-molecule antagonists of MDM2. Science. 2004;303(5659):844-848.

102. Dutertre M, Sanchez G, Barbier J, Corcos L, Auboeuf D. The emerging role of pre-messenger RNA splicing in stress responses: sending alternative messages and silent messengers. RNA Biol. 2011;8(5):740-747.

103. Grover R, Ray PS, Das S. Polypyrimidine tract binding protein regulates IRES-mediated translation of p53 isoforms. Cell Cycle. 2008;7(14):2189-2198.

104. Montanaro L, Calienni M, Bertoni S, et al. Novel dyskerin-mediated mechanism of p53 inactivation through defective mRNA translation. Cancer Res. 2010;70(11):4767-4777.

105. Sharathchandra A, Lal R, Khan D, Das S. Annexin A2 and PSF proteins interact with p53 IRES and regulate translation of p53 mRNA. RNA Biol. 2012;9(12):1429-1439.

106. Weingarten-Gabbay S, Khan D, Liberman N, et al. The translation initiation factor DAP5 promotes IRES-driven translation of p53 mRNA. Oncogene. Epub January 14, 2013.

107. Camus S, Ménendez S, Fernandes K, et al. The p53 isoforms are differentially modified by Mdm2. Cell Cycle. 2012;11(8):1646-1655.

108. Secchiero P, Bosco R, Celeghini C, Zauli G. Recent advances in the therapeutic perspectives of Nutlin-3. Curr Pharm Des. 2011;17(6): 569-577. 


\section{Publish your work in this journal}

OncoTargets and Therapy is an international, peer-reviewed, open access journal focusing on the pathological basis of all cancers, potential targets for therapy and treatment protocols employed to improve the management of cancer patients. The journal also focuses on the impact of management programs and new therapeutic agents and protocols on patient perspectives such as quality of life, adherence and satisfaction. The manuscript management system is completely online and includes a very quick and fair peer-review system, which is all easy to use. Visit http://www.dovepress.com/testimonials.php to read real quotes from published authors.

Submit your manuscript here: http://www.dovepress.com/oncotargets-and-therapy-journal 